\title{
INFLUENCE OF UNEVEN TIRE INFLATION PRESSURE ON VEHICLE DYNAMICS DURING BRAKING
}

\author{
Algirdas Janulevicius ${ }^{1,2}$, Gediminas Pupinis ${ }^{1}$ \\ ${ }^{1}$ Vytautas Magnus University, Lithuania; ${ }^{2}$ Klaipeda State University of Applied Sciences, Lithuania \\ algirdas.janulevicius@vdu.lt, gediminas.pupinis@vdu.lt
}

\begin{abstract}
The main problems in the operation of road transport vehicles today are related to safety, economy and environmental impact. The performances by the vehicles are closely linked to tires, their selection and the quality of their operation. Tire pressure strongly influences on the interaction between the wheels and the road, i.e. tire-road adhesion and rolling resistance. Proper tire pressure increases fuel economy, reduces the braking distance, improves vehicle control and extends the tire life. It is known that deterioration of control of the vehicle and braking efficiency and quality will reduce the safety of passengers. It is believed that uneven tire inflation pressure can significantly reduce the braking performance and vehicle stability. The purpose of this study is to determine the effect of tire inflation pressure inequality on the longitudinal and lateral acceleration of the vehicle when braking at maximum braking force. Maximum braking force of the vehicle is a function of the tire/road adhesion coefficient and the vertical load on the wheels. The value of the coefficient of tire/road adhesion in turn depends on the inflation pressure of the tire. For these reasons, it is appropriate to assess the impact of the vehicle tire pressure inequality on the braking performance. Studies have shown that the dynamics of a braked vehicle is greatly influenced by uneven tire inflation pressure. It was found that the lateral braking acceleration increased from 1.5 to $3.8 \mathrm{~m} \cdot \mathrm{s}^{-2}$ at maximum braking force, when the vehicle speed was $80 \mathrm{~km} \cdot \mathrm{h}^{-1}$.
\end{abstract}

Keywords: vehicle, tire, pressure, braking, force, efficiency.

\section{Introduction}

The reliability of a vehicle depends to a large extent on its operation and compliance with the operating rules laid down by the manufacturer. The main problems in the operation of road transport vehicles today are related to safety, economy and environmental impact. The performances by vehicles are closely linked to tires, their selection and the quality of their operation. The main purpose of the tire is to cushion the impact on the car chassis due to rough road, to provide a reliable grip between the wheels and the road surface, to transmit traction and braking forces to the road surface. In addition, tires help to ensure the vehicles stability on the road. Smaller width of the tire reduces the adhesion to the dry road surface, but facilitates wet driving and reduces the tire noise and fuel consumption [1-3].

Proper inflation pressure tires are the most important factor in ensuring a good automobile performance. Insufficiently inflated tires make the vehicle more difficult to control. Unevenly inflated tires further impair vehicle control. The results of studies reported in literature indicate that braking deceleration, just as vehicle acceleration, determines the dynamics and safe speed of the car. In addition, effective braking increases the road safety. It is important that the braking distance is as short as possible (greater deceleration), so that the vehicle does not lose its balance and is controlled and steered [4-6].

When the vehicle is in motion, there is always a process of rolling and sliding between the tire and the road surface $[7 ; 8]$. Rolling resistance is characterized by a coefficient calculated as the ratio of tangential to normal forces. Wheel slip is evaluated by a slip factor, which is equal to the ratio of the tire adhesion surface to the wheel centre speed relative to the road surface [9]. The dependencies of these coefficients are analogous to those of the tire in both traction and braking modes (Fig. 1). It can be seen from Figure $1 a$ that when the wheel is braked to the maximum slip value, the coefficient of adhesion of the tire increases initially and then decreases as the slip increases. The best adhesion between tires is when the wheel slip is $8-15 \%[1 ; 9 ; 10]$. When the tire slips completely, the value of its coefficient of adhesion to the road decreases by $20-30 \%[1 ; 9 ; 10]$. Analysing the forces acting on the tire-to-road adhesion surface, we can see that the pressure produces the normal (perpendicular to the road) and tangential (parallel to the road, i.e. in terms of $\mathrm{x}$ and $\mathrm{y}$ coordinates) components of the force $[7 ; 11-13]$. The distribution of pressures on the adhesion surface is shown in Figure $1 b$. It can be seen from the figure (Fig. 1b) that the pressure distribution in the adhesion area depends on the normal (z coordinate) longitudinal forces ( $x$ coordinate) and the transverse forces (y coordinate), which characterize the vehicle motion. 

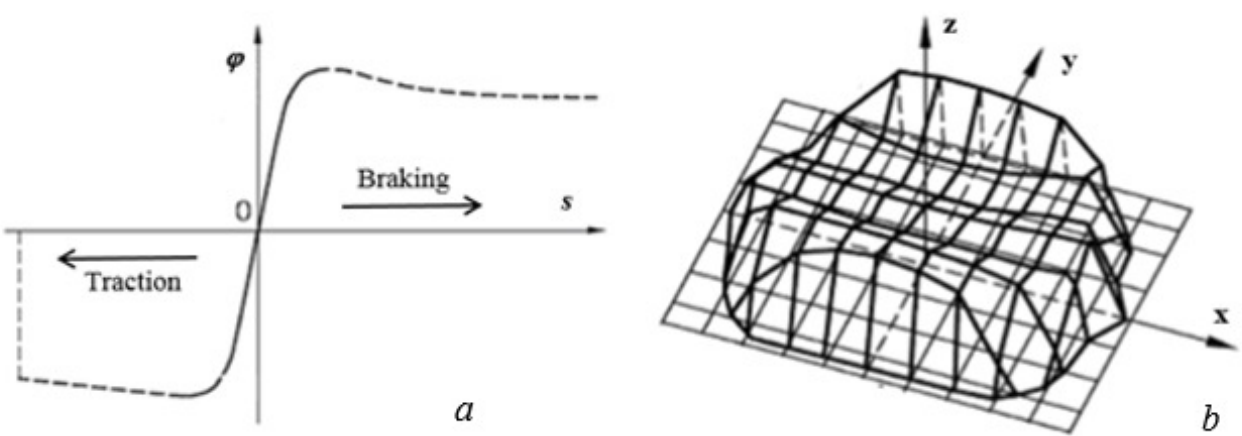

Fig. 1. Tire interaction with the road surface: $a$ - dependence of the adhesion coefficient on tire slip; $b$ - distribution of tire-to-road contact pressure force

The forces acting on the tire-to-road adhesion surface area are influenced by the tire pressure, vertical tire load, travel speed, and other factors [7; 14-16]. In summary, scientific sources are constantly paying attention to assessing the performance of vehicles, but some issues, such as the analysis of tire pressure differences, are not sufficiently examined. For these reasons, a scientific problem has been raised in this article: to investigate the influence of uneven tire inflation pressure on the car braking main performance.

\section{Materials and methods}

The Opel Astra 1.7 CDTI passenger car, manufactured in Germany in 2007, weighs $1365 \mathrm{~kg}$, with an engine power of $74 \mathrm{~kW}$ and a displacement of $1686 \mathrm{~cm}^{3}$, was selected for testing. During preparation for scheduled tests, the car was serviced, equipped with manufacturer-recommended brake pads and new tires STARFIRE (COOPER) W200 (T) 205/55R16 91T. In these tests, the maximum and the average deceleration in the longitudinal and lateral directions of the car were investigated by reducing the inflation pressure to 190,150 and $110 \mathrm{kPa}$ of one tire at constant pressure of other tires $(220 \mathrm{kPa})$, when the speed before the start of braking was $80 \mathrm{~km} \cdot \mathrm{h}^{-1}$ and $40 \mathrm{~km} \cdot \mathrm{h}^{-1}$. The AccDriver 211 Gauge, measuring range $\pm 2 \mathrm{~g}\left( \pm 20 \mathrm{~m} \cdot \mathrm{s}^{-2}\right)$ and measurement accuracy $0.04 \mathrm{~m} \cdot \mathrm{s}^{-2}$, was used for acceleration in the longitudinal and lateral directions. The AccDriver 211 comes with memory and automatically saves test data. The device is activated before the test while the vehicle is stationary. During the test, the device automatically records the acceleration and deceleration of the vehicle. There is no need to switch the device on or off during the test. Measurements made with this device allow to obtain graphs of the variations in the longitudinal and lateral acceleration of the vehicle from time to time in ms (Fig.2).

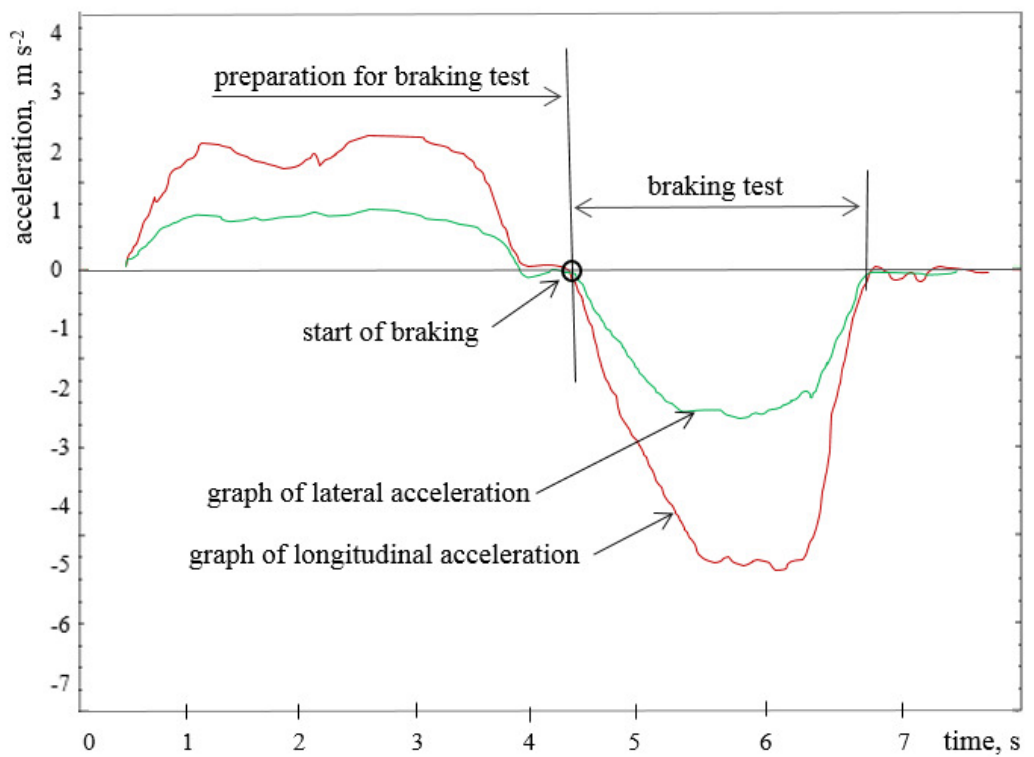

Fig. 2. Example of graph of measurement results of longitudinal and lateral acceleration of braked vehicle 
Depending on the obtained longitudinal and lateral acceleration variation data and graphs, the maximum and average deceleration dependencies were found at various tire inflation pressures at 40 and $80 \mathrm{~km} \cdot \mathrm{h}^{-1}$. The research was conducted in 2019 October, on a straight stretch of a horizontal asphalt road in the territory of Vytautas Magnus University Agricultural Academy. The measurements were repeated three times for each of the intended test variants.

\section{Results and discussion}

In the first stage of the study, the maximum deceleration of the car and the average deceleration at different tire inflation pressures $(110,150,190$ and $230 \mathrm{kPa})$ were determined at speeds 40 and $80 \mathrm{~km} \cdot \mathrm{h}^{-1}$. Figure 1 shows the experimental dependence of vehicle braking acceleration on tire pressure, which is varied uniformly on all wheels.
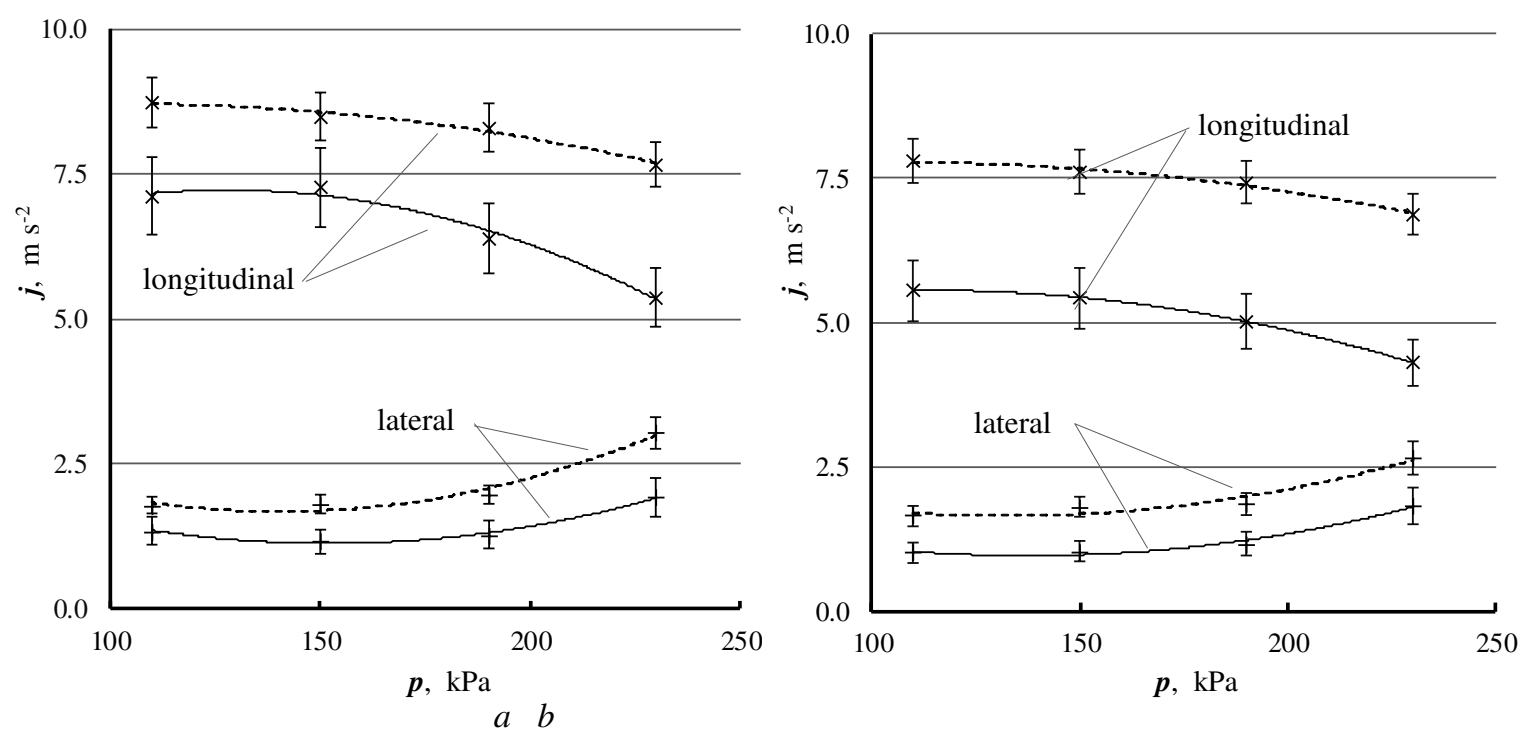

Fig. 3. Influence of tire pressure on vehicle deceleration in the longitudinal and lateral directions at speed: $a-80 \mathrm{~km} \cdot \mathrm{h}^{-1}$ and $b-40 \mathrm{~km} \cdot \mathrm{h}^{-1}$. Dashed lines show applications of the maximum deceleration, solid lines show the average deceleration

The dependencies shown in Figure 1 represent the braking acceleration in the longitudinal and lateral directions at the maximum braking force of the vehicle. The results showed that at the speed $80 \mathrm{~km} \cdot \mathrm{h}^{-1}$, the average deceleration of the vehicle in the longitudinal directions ranged from 5.0 to $7.5 \mathrm{~m} \cdot \mathrm{s}^{-2}$, while the lateral deceleration ranged from 1.2 to $2.4 \mathrm{~m} \cdot \mathrm{s}^{-2}$. It should be noted that lower tire pressure significantly improved the vehicle deceleration in the longitudinal direction. It should also be noted that at lower tire pressures, lower vehicle deceleration in lateral directions was observed. This is explained by the fact that a reduction in the tire pressure improves the adhesion of the tires on the road $[4 ; 8 ; 10 ; 11 ; 17]$. A similar dependence of deceleration was found in tests at the vehicle speed of $45 \mathrm{~km} \cdot \mathrm{h}^{-1}$. It should be noted here that lower deceleration values in both longitudinal and lateral directions were observed when the vehicle speed was reduced.

In the next phase of the study, the maximum and the average deceleration of the car were determined by reducing the inflation pressure to 190,150 and110 $\mathrm{kPa}$ of one front wheel (right) tire at constant pressure of other tires $(220 \mathrm{kPa})$, when the speed to braking was $80 \mathrm{~km} \cdot \mathrm{h}^{-1}$ and $40 \mathrm{~km} \cdot \mathrm{h}^{-1}$. The dependence of the vehicle braking acceleration in the longitudinal and lateral directions on the variation of the pressure in one front (right) tire is shown in Figure 4. The results show that the lower pressure in one front tire significantly increased the vehicle acceleration in the lateral direction, whereas the increase in the longitudinal direction was not significant. Reducing the pressure in the front right tire from $230 \mathrm{kPa}$ to $110 \mathrm{kPa}$ (at speed $80 \mathrm{~km} \cdot \mathrm{h}^{-1}$ before braking) increased the average lateral acceleration of the vehicle by $2.0 \mathrm{~m} \cdot \mathrm{s}^{-2}$ and by about $0.25 \mathrm{~m} \cdot \mathrm{s}^{-2}$ in the longitudinal direction.

In the final stage of this study, the maximum and average deceleration of the car was determined by reducing the inflation pressure of one rear wheel (right) tire to 190,150 and $110 \mathrm{kPa}$ at constant pressure of other tires $(220 \mathrm{kPa})$, when speed to braking was $80 \mathrm{~km} \cdot \mathrm{h}^{-1}$ and $40 \mathrm{~km} \cdot \mathrm{h}^{-1}$. The dependence of the vehicle braking acceleration in the longitudinal and lateral directions on the variation of the 
pressure in one front (right) tire is shown in Figure 5. It was found that reducing the pressure in the rear right tire from $230 \mathrm{kPa}$ to $110 \mathrm{kPa}$ increased the vehicle acceleration in the lateral direction by $1.5 \mathrm{~m} \cdot \mathrm{s}^{-2}$ and in the longitudinal direction by $7.5 \mathrm{~m} \cdot \mathrm{s}^{-2}$ at a maximum braking force, when the speed before the start of braking was $80 \mathrm{~km} \cdot \mathrm{h}^{-1}$. The vehicle acceleration was also found to increase by 1.5 $\mathrm{m} \cdot \mathrm{s}^{-2}$ in the lateral direction and by $7.5 \mathrm{~m} \cdot \mathrm{s}^{-2}$ in the longitudinal direction, when the speed before the start of braking was $40 \mathrm{~km} \cdot \mathrm{h}^{-1}$.
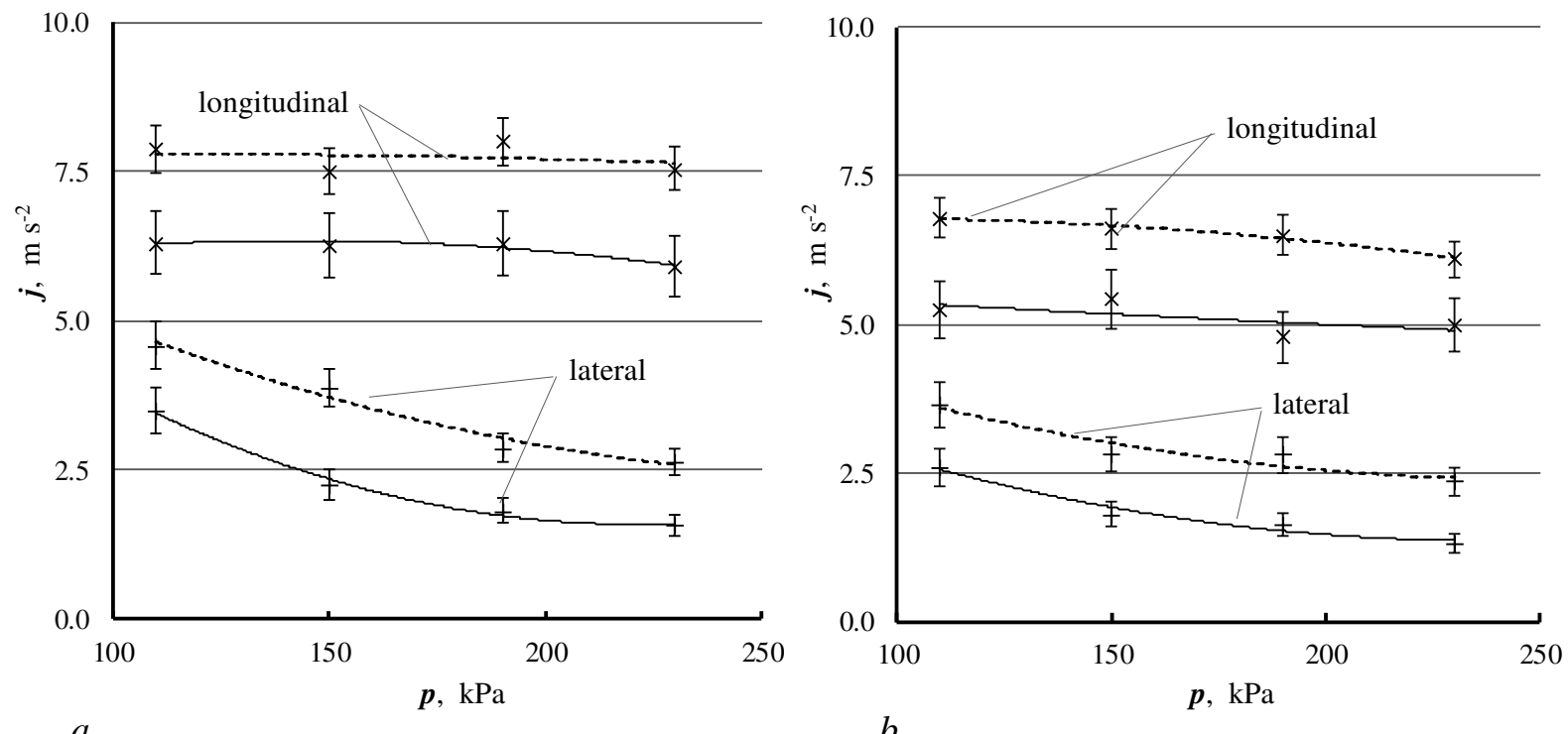

Fig. 4. Influence of pressure reduction of one front (right) tire on deceleration of the vehicle in longitudinal and lateral directions at constant pressure of other tires $(220 \mathrm{kPa})$, when the traveling speed to braking: $a-80 \mathrm{~km} \cdot \mathrm{h}^{-1}$ and $b-40 \mathrm{~km} \cdot \mathrm{h}^{-1}$. Dashed lines show applications of the maximum deceleration, solid lines show the average deceleration
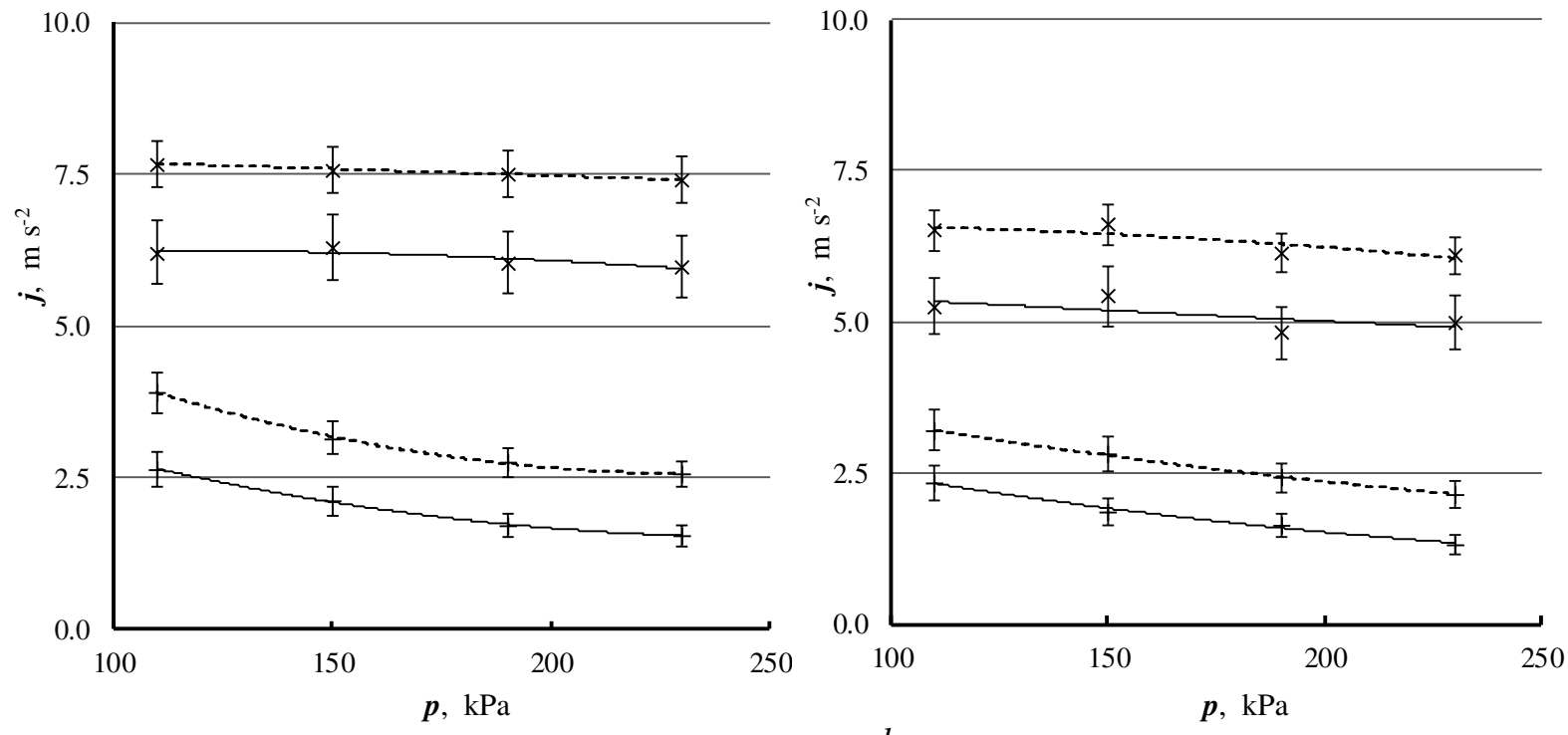

\section{$b$}

Fig. 5. Influence of pressure reduction of one front (right) tire on deceleration of the vehicle in longitudinal and lateral directions at constant pressure of other tires $(220 \mathrm{kPa})$, when the traveling speed to braking: $a-80 \mathrm{~km} \cdot \mathrm{h}^{-1}$ and $b-40 \mathrm{~km} \cdot \mathrm{h}^{-1}$. Dashed lines show applications of the maximum deceleration, solid lines show the average deceleration

The results show that the lower pressure in one tire significantly increased the vehicle acceleration in the lateral direction. This was due to the uneven deformation of all the tires. The lower pressure in one tire increased its deformation and adhesion area to the road and improved the adhesion between that tire and the road. The studies have shown that increase of the lateral acceleration of the vehicle is more influenced by the pressure change in one front tire, when the vehicle speed is higher. 


\section{Conclusions}

1. It was found that uneven tire pressure increased the vehicle acceleration in the lateral direction. The lateral acceleration of the vehicle increases more influenced by the uneven tire pressure change in the front tire, when the vehicle speed is higher.

2. It was determined that reducing the pressure in one front tire from $230 \mathrm{kPa}$ to $110 \mathrm{kPa}$ increased the vehicle acceleration in the lateral direction by $1.5 \mathrm{~m} \cdot \mathrm{s}^{-2}$ at a maximum braking force, when the speed before the start of braking was $80 \mathrm{~km} \cdot \mathrm{h}^{-1}$, and $1.5 \mathrm{~m} \cdot \mathrm{s}^{-2}$, when the speed before the start of braking was $40 \mathrm{~km} \cdot \mathrm{h}^{-1}$.

3. Unambiguous road safety is affected by the vehicle acceleration in the longitudinal and lateral directions, so uneven tire pressure when braking the vehicle remains an important area of investigation.

\section{References}

[1] Raslavičius L., Pakalnis A., Keršys A. etc. Investigation of asphalt texture roughness on friction evolution for wheeled vehicles. Transport, 31(2), 2016, pp. 133-141.

[2] Žuraulis V, Levulyte L, Sokolovskij E. The Impact of Road Roughness on the Duration of Contact Between a Vehicle Wheel and Road Surface, Transport, 29(4), 2014, pp. 431-439.

[3] Viehweger M., Vaseur C., Aalst S. etc. Vehicle state and tyre force estimation: demonstrations and guidelines, Vehicle System Dynamics, 2020, DOI: 10.1080/00423114.2020.1714672

[4] Li P., Xu H. Braking efficiency and stability of chassis braking system of combine harvester: the theoretical derivation and virtual prototype simulation. Mathematical Problems in Engineering, 2019, pp. 1-18.

[5] Van der Merwe N.A., Els P.S., Žuraulis V. ABS braking on rough terrain. Journal of Terramechanics, 80, 2018, pp. 49-57.

[6] Velenis E., Tsiotras P., Canudas-De-Wit C. etc. Dynamic tyre friction models for combined longitudinal and lateral vehicle motion. Vehicle System Dynamics, 43(1), 2005 pp. 3-29.

[7] Bafet G., Charara A., Lechner D. Estimation of vehicle sideslip, tire force and wheel cornering stifness. Control Engineering Practice, 17(11), 2009, pp. 1255-1264.

[8] Janulevičius A., Gurevičius P. Impact of the inflation pressure of the tires on lead of front drive wheels and movement resistance force of tractors. Transport, 34(6), 2019, pp. 628-638.

[9] Ghandour R., Victorino A., Charara A. A vehicle skid indicator based on maximum friction estimation. Proceedings of the 18th World Congress the International Federation of Automatic Control Milano (Italy), 2011, pp. 2272-2277.

[10] Genta G, Morello L. The automotive chassis: volume 1: components design. Springer, Dordrecht, 2009. https://www.springer.com/gp/book/9781402086748

[11] Jimenez E., Sandu C. Towards a real-time pneumatic tire performance prediction using an advanced tire-ice interface model. Journal of Terramechanics, 81, 2019, pp. 43-56.

[12] Panáček V., Semela M., Adamec V., Schüllerová B. Impact of usable coefficient of adhesion between tyre and road surface by modern vehicle on its dynamics while driving and braking in the curve. Transport, 31(2), 2016, pp. 142-146.

[13] Taheri S., Sandu C., Taheri S. etc. A technical survey on Terramechanics models for tire-terrain interaction used in modeling and simulation of wheeled vehicles. Journal of Terramechanics, 57, 2015, pp. 1-22.

[14] Osinenko P.V., Geissler M., Herlitzius T. A method of optimal traction control for farm tractors with feedback of drive torque. Biosystems engineering, 129, 2015, pp. 20-33.

[15] Čiplienè A., Gurevičius P., Janulevičius A. etc. Experimental validation of tyre inflation pressure model to reduce fuel consumption during soil tillage. Biosystems engineering, 186, 2019, pp. 4559.

[16] Diserens E., Defossez P., Duboisset A. etc. Prediction of the contact area of agricultural traction tyres on firm soil. Biosystems engineering, 110, 2011, pp. 73-82.

[17] Singh K.B., Arat M.A., Taheri S. Literature review and fundamental approaches for vehicle and tire state estimation. Vehicle System Dynamics, 57(11), 2019 pp. 1643-1665. 